$\xi=-1$ 国

\title{
Student Information System and Performance Retrieval Through Dashboard
}

\author{
K.V.Phani Krishna ${ }^{1 *}$, M.Mani Kumar ${ }^{2}$, P.S.G.Aruna $\mathrm{Sri}^{3}$ \\ ${ }^{1}$ Department of Electronics and Computer Science Engineering, KLEF, Vaddeswaram. \\ ${ }^{2}$ Department of Electronics and Computer Science Engineering, KLEF, Vaddeswaram. \\ ${ }^{3}$ Assoc. Professor Department of Electronics and Computer Science Engineering, KLEF, Vaddeswaram. \\ *Corresponding author E-mail: manikumar.klu@gmail.com
}

\begin{abstract}
The principle focal point of information mining is to gather diverse information from databases or information ware houses and the data gathered that had never been known, it is legitimate and operational. Instructive establishments can utilize this to keep up all the data of understudy scholastics effectively which is basically imperative. The execution of understudies in their scholastics is a defining moment for their brightest vocation. Foreseeing understudy scholarly execution has been a basic research point in Educational Data Mining $(\mathrm{EDM})$ which utilizes machine learning and information mining methods to look at information from illuminating settings. Estimating understudy scholarly execution is trying since it relies upon different elements. Grouping and Prediction are among the significant procedures in information mining and assumes an essential part in EDM. The requirement for this is to empower the college to mediate and give help to low achievers as right on time as conceivable. In this examination we build up a grouping model usingC4.5 calculation for area savvy execution assessment framework for designing understudies. It additionally brings network between educators, understudies and guardians by keeping them refreshed with their kid execution consistently. The entire framework will be accessible through a protected, online interface inserted in school site.
\end{abstract}

Keywords: C4.5 calculation; Decision tree; Instructive Data mining; Performance forecast; Student data framework.

\section{Introduction}

Student data framework The fundamental reason for planning and execution of a complete understudy data framework and client interface is to supplant the present paper records. The framework gives staff UI which can get to all parts of a student's scholarly advance through a safe, on the web interface inserted in the colleges site. Notwithstanding this it additionally gives understudy and parent UI, permitting clients to get to data. The framework utilizes client verification, showing just pertinent information. Every subsystem has confirmation enabling approved clients to make or refresh information in that sub-framework. Examining understudies' information and data to order understudies, or to make choice trees or affiliation rules, to settle on better choices or to improve understudies execution is an intriguing field of research, which predominantly centers around breaking down and understanding understudies' instructive information that demonstrates their instructive execution, and produces particular principles, characterizations, and expectations to help understudies in their future instructive execution.

Grouping is the most natural and best information mining procedure used to group and foresee esteems. Instructive Data Mining $(E D M)$ is no special case of this reality, henceforth, it was utilized as a part of this exploration paper to dissect gathered understudies' data through a review, and give arrangements in light of the gathered information to foresee and arrange understudies' execution in their up and coming semester. The goal of this investigation is to distinguish relations between understudies individual and social elements, and their scholarly execution. This newfound learning can help understudies and also teachers in completing better improved instructive quality, by recognizing conceivable under performers toward the start of the semester/year, and apply more regard for them so as to enable them in their instruction to process and improve marks. In actuality, not just under performers can profit by this exploration, yet in addition conceivable well entertainers can profit by this investigation by utilizing more endeavors to direct better ventures and look into through having more help and consideration from their teachers.

All information is put away safely on SQL servers oversaw by school manager. All the validation points of interest like username, secret word and so forth are sent through an email to the enlisted id. Beforehand, this records were put away on papers which had numerous downsides. This framework gives a basic interface for the upkeep of understudy data. Accomplishing this is troublesome utilizing customary technique as the information is scattered, excess and time expending. This framework centres around demonstrating information in an simple and shrewd way to understudies, school staff and guardians. 
EDM utilizes machine learning and information mining methods to investigate information from instructive settings to discover expectations that describe understudies conduct and execution. This is an incredible worry to the administration as scholarly execution relies upon various components. Information mining systems can be connected on understudy informational collections to foresee their execution. Foreseeing understudy execution enhances their scholarly outcomes. By this administration can locate the powerless purpose of understudies furthermore, straightforwardly focus on that point to enhance which can improve workforce for country's advancement. These days nature of an understudy matters the most along these lines, other than showing this kind of additional consideration is basic

\section{Related work}

EDM has developed as an exceptionally dynamic research territory the same number of thing in this field are not uncovered. Work associated with understudy execution, personnel execution and effect on this on understudies last execution needs consideration.

- The paper delineates the clients, segments and the different methodologies in EDM.

- In this paper a methodology to enhance the students execution is specified by mapping the students record utilizing K-mean bunching calculation and gathering datasets into group however there is no future execution expectation.

- Bharadwaj and Pal[6] proposed ID3 choice tree calculation as an arrangement model to foresee the understudies division, the past data, for example investment, class test, workshop and undertaking marks were gathered from the understudy's past databases to imagine the execution toward the total of semester. This helped the understudies and the instructors to enhance the division of the understudies.

- Uses two game plan count J48 and Random tree to predict execution of MCA understudy in this work sporadic has better precision and it exhaust less time than J48 figuring. So forecast of understudy execution utilizing irregular tree characterization calculation can be more productive than $\mathrm{J} 48$.

- Presented a profound learning engineering for foreseeing execution via consequently taking in different levels of portrayal.

- Uses grouping calculation ID3 and C4.5 to distinguish different classifications of understudies execution. It moreover infers that the execution of $\mathrm{C} 4.5$ calculation is high contrasted with other.

- The model predicts student's future learning results utilizing informational collections of senior understudies utilizing J48 calculation which turned out to be exact than other.

- An electronic framework is made which deals with all the understudy related information. This framework is made using HTML, CSS, Java content, PHP, SQL.
- This paper proposes an android application for the administration of understudy data which robotizes the existing manual framework.

- Decision tree can be utilized on understudies past execution information to produce the model and this model can be utilized to foresee the execution[5]. It will empower to distinguish the understudies ahead of time who are in danger. Giving cautioning to the understudies those are on danger of fizzling the understudies can enhance their execution.

\section{Choice tree algorithms}

There are numerous choice tree calculations, for example, CART, ID3, C4.5 can be utilized for anticipating understudies execution. In this paper $\mathrm{C} 4.5$ has been utilized to make choice tree.

\subsection{C4.5 (j48) calculation}

This calculation[7] is a successor to ID3 created by Quinlan Ross. The Hunts algorithm.C4.5 calculation produces the rules from which specific character of that information is produced. The goal is logically speculation of a choice tree until the point when it picks up harmony of adaptability and exactness. C4.5 has the idea of Gain Ratio as an ascribe choice measure to make a choice tree. C4.5 utilizes critical pruning to dispose of unessential branches inside the choice tree to upgrade the precision of characterization.

\subsection{Overlap cross-approval}

At the point when the information is less at that point overlap cross approval can be utilized. In this the first example is haphazardly apportioned into $\mathrm{k}$ subsamples. Of the $\mathrm{k}$ subsamples, a lone subsample is taken as the endorsement data for testing the illustrate and whatever is left of the $\mathrm{k}-1$ subsamples are used as planning data. The cross endorsement process is then reiterated $\mathrm{k}$ times with each one of the $\mathrm{k}$ subsamples used absolutely once as the endorsement data. The $\mathrm{k}$ comes to fruition in view of the folds by then can be touched base at the midpoint of (or solidified) to make a singular judgment.

\section{Proposed framework}

Framework outline EDM has a lot of information that must be masterminded in reliable way. To improve existing framework the proposed demonstrate is planned by gathering information and ordering them in light of understudy execution in a specific space. The execution is delegated
[1] Poor
[2] Average
[3] fantastic

the framework structure is as appeared beneath which gives a productive investigation on understudy execution by information gathering and forecast. 


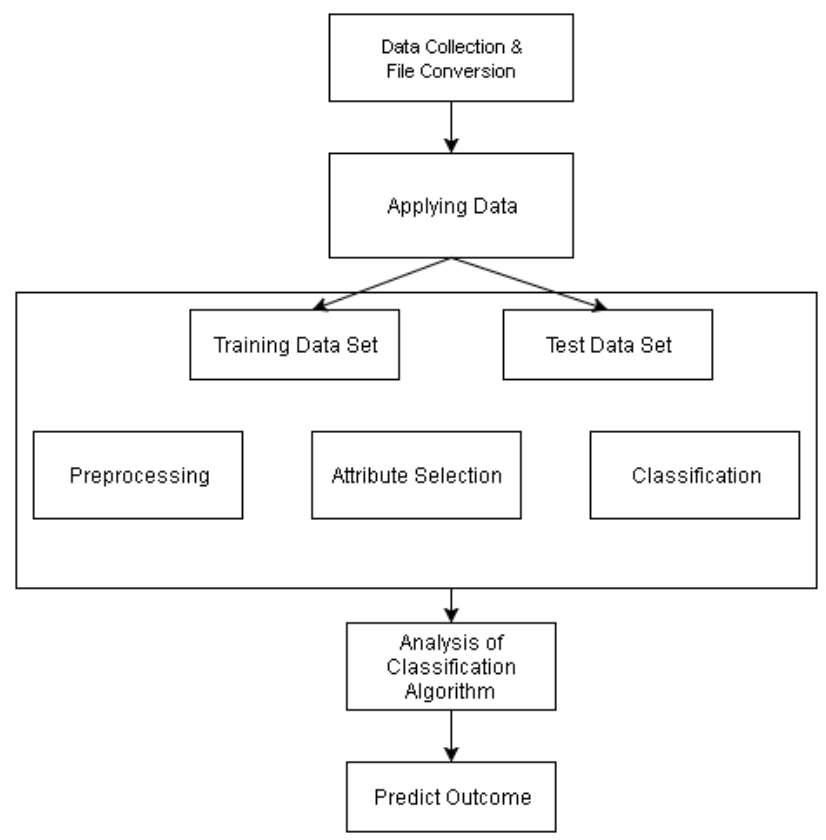

Fig. 1: System framework

\section{Methodology}

In this area the means of customary KDD process would be taken after. The procedure begins from information accumulation and information pre-preparing took after by characterisation show development and closures with display assessment and understandings. Ventures in KDD process

\subsection{Data gathering}

The informational collection for contemplate has been gathered from examination cell. The investigation considers the scholarly execution of understudies from semester 1 to semester 7 of B.E program. At first information is gathered in an exceed expectations sheet which gathers every one of the evaluations of all semesters.

\subsection{Pre-handling}

\subsubsection{Choice of attributes}

There might be numerous traits accessible however all the property is not helpful for expectation. So just the important characteristics are thought about to choose the qualities.

\subsubsection{Choosing esteems for attributes}

It is important to choose esteems for credits to maintain a strategic distance from ceaseless information. This should be possible by utilising discrete information.

\subsection{Demonstrate building}

In this stage, choice tree has been chosen as a classifier under cross approval technique. For display development C4.5 choice tree technique is utilised in view of traits chosen. The property having greatest pick up proportion esteem is chosen for part the hub. This procedure proceeds till the whole tree is fabricated. Fig.2 demonstrates the choice tree development. Leaf hubs are spoken to by rectangle and root hub by oval.

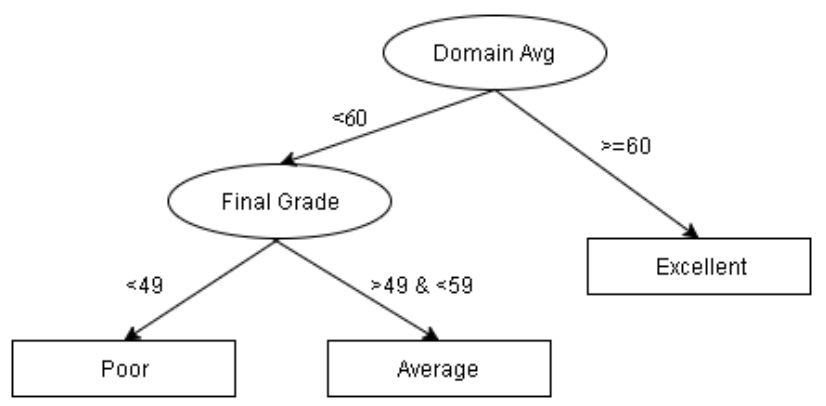

Fig 2: choice tree development

\subsection{Translation}

The expectation of the outcome should be possible for all the areas.

\subsubsection{Prediction for programming domain:}

The outcome appeared here is for programming area. Taking into thought the imprints acquired in programming area subjects like Structured Programming approach (spa), OOPM, information structures, examination of calculation

E.g. on the off chance that normal signs of the area is from 35 to 49 at that point Poor. On the off chance that between 55 to 59 then normal. In the event that between 65 to 80 then superb

(AOA) from various semesters the expectation of the understudy execution in that specific area should be possible. The choice tree for programming area show in fig3

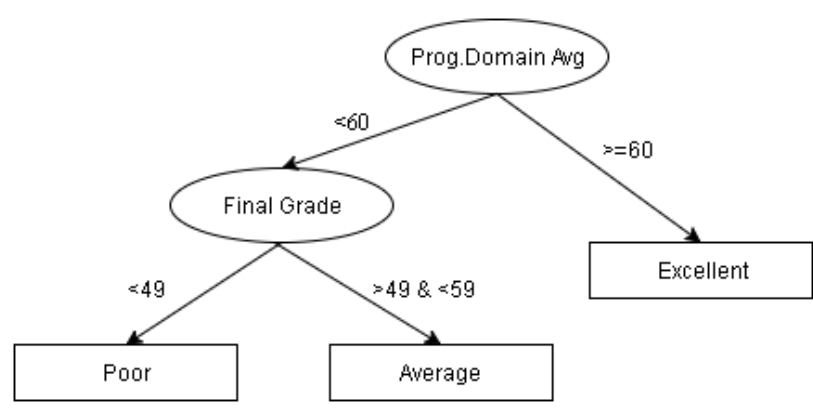

Fig. 3: Choice tree for programming

\subsubsection{Rules created for programming domain:}

1. If the normal space marks is more prominent than or equivalent to $60(>=60)$ at that point the execution of understudy is phenomenal.

2. if normal area marks is under $60(<60)$ what's more, last checks are in the scope of $49-59$ then the execution is normal

3. if normal area marks is under $60(<60)$ and last stamps are under 49 then the execution in that space is poor. As should be obvious from the above choice tree, the root characteristic is normal signs of programming area. On

the off chance that the normal imprints is more than 60 than the understudy is astounding in programming subjects. On the off chance that he gets normal stamps less than 49 than he is poor in that area. Also extraordinary principles can be produced for various areas like Theory and Concepts space, Networking area, 
Maths and Logic space, S/w advancement space by arranging subjects into this spaces and taking the normal of characteristics of the considerable number of subjects in that specific area.

\section{Conclusion and future work}

This paper mainly deals with the Educational Data mining fundamental concentration is to break down the training framework. This paper shows grouping technique to anticipate understudy execution. It likewise aid robotizing the current manual framework by giving the Electronic Information System. It makes network amongst guardians and school. Every one of the partners, personnel furthermore, administration can get the required data without delay. This entire model can be helpful in instructive framework like MCT Rajiv Gandhi Institute of Technology, Mumbai. Consequently enhancing their measures and performance. The consequences of the information digging calculations for the grouping of the understudies in view of the qualities chosen uncovers that the forecast rates are not uniform. The work can be additionally stretched out by outlining the understudy display dissecting records of understudies extracurricular aptitudes and give a proposals on correspondence and specialized aptitude improvement by which understudies can be worked in proficient part of gifts.

\section{References}

[1] Sonali Agarwal, G. N. Pandey, and M. D. Tiwari, Data Mining in Education: Data Classification and Decision Tree Approach, 2012.

[2] Zhibing Liu, Huixia Wang,Hui Zan "Design and implementation of student information management system." 2010 International symposium on intelligence information processing and trusted computing. 978-0-7695- 4196-9/10 IEEE

[3] Nikhil Rajadhyax, Rudresh Shirwaikar, Data Mining on Educational Domain, 2012.

[4] Manasi Kawathekar, Kirti K.Bhate and Pankaj Belgoankar "An Android Application for Student Information System" International Journal of Advanced Research in Computer Engineering \& Technology (IJARCET) Volume 4 Issue 9, Sept 2015

[5] R. R. Kabra And R. S. Bichkar(2011),„Performance Prediction Of Engineering Students Using Decision Treesl, International Journal Of Computer Applications (0975 - 8887) Volume 36No.11, December 2011.

[6] Baradwaj Brijesh Kumar and Pal Saurabh (2011).Mining Educational Data to Analyze Student Performance. International Journal

[7] Parneet Kaura, Manpreet Singh, Gurpreet Singh Josanc "Classification and Prediction based Data Mining Algorithms to Predict Slow Learners in Education Sector" Science Direct Procedia Computer Science 57 ( 2015 ) 500 - 5082015 (ICRTC2015).

[8] Data Mining: A prediction for Student's Performance Using Classification Method Abeer Badr El Din Ahmed, Ibrahim Sayed Elaraby 